\title{
Influence of Surface Treatments on Fatigue Strength of Ti6Al4V Alloy
}

\author{
Kyo Takahashi and Eiichi Sato \\ Motorcycle R\&D Center, Honda R\&D Co. Ltd., Asaka 351-8555, Japan
}

Titanium alloys do not exhibit good seizure toughness. In general, a surface treatment must be applied if the component is subjected to sliding contact. For surface hardening, it is well known that oxygen and nitrogen treatments can be used because they are easily available, inexpensive elements. However, these treatments cause the fatigue strength to decrease which is a problem.

The reason for the fatigue strength decrease due to oxygen diffusion treatment is residual tensile stress on the surface. Shot peening is an effective technique to improve the fatigue strength of oxygen diffusion treated titanium. This report details the effects on fatigue strength due to surface treatments such as notch and shot peening. [doi:10.2320/matertrans.MA200901]

(Received June 1, 2009; Accepted January 15, 2010; Published March 25, 2010)

Keywords: titanium, surface treatment, surface hardening, oxygen diffusion, seizure, fatigue strength, shot peening

\section{Introduction}

Titanium alloys are effective for reducing the weight of engine parts and are superior to steel in terms of the strengthto-weight ratio.

Titanium alloys are used in such components as connecting rods and engine valves for high-performance engines and racing applications. Lightweight titanium alloys are also effective for reducing fuel consumption and engine friction.

However, it is necessary to apply some type of surface treatment to improve wear resistance, because titanium alloys have poor seizure characteristics. Typical surface treatments for titanium are expensive, for example ion-plating and Mo spray. ${ }^{1-6)}$

Recently, an inexpensive hardening process using oxygen and nitrogen has been developed. ${ }^{7-9)}$ Improvements in the fatigue strength of steel have been reported by changing the surface layer through shot peening. ${ }^{10,11)}$ To obtain good seizure toughness in titanium, inexpensive and ubiquitous elemental nitrogen and oxygen can be used. However, the fatigue strength is changed by surface treatments. We report the influence of different surface conditions and surface treatments (Oxygen diffusion treatment and shot peening) on the fatigue strength of Ti6Al4V alloy in this report.

\section{Experimental}

We used the general-purpose titanium alloy, Ti6Al4V, in its annealed condition ( $993 \mathrm{~K}$ for $7.2 \mathrm{ks}$ ) to make test specimens. Table 1 shows the chemical composition of the experimental test specimen material. The OD (Oxygen diffusion) treatment forms a surface hardened diffusion layer by heat treating in an atmosphere furnace.

OD treatment improves the seizure toughness of titanium alloys through hardening of the surface layer by oxygen diffusion. Atmosphere management of furnace is not controlled. The test specimen is furnace cooled, from a temperature of $973 \mathrm{~K}$ for $18 \mathrm{ks}$. Tensile properties, charpy impact tests and fatigue tests were then performed. Tensile strength test specimens were prepared according to JIS14A. Figure 1 shows a typical tensile test specimen. Charpy impact specimens were prepared according to JIS Z 2242, Fig. 2 shows a
Table 1 Chemical compositions of Ti-6Al-4V used in this study.

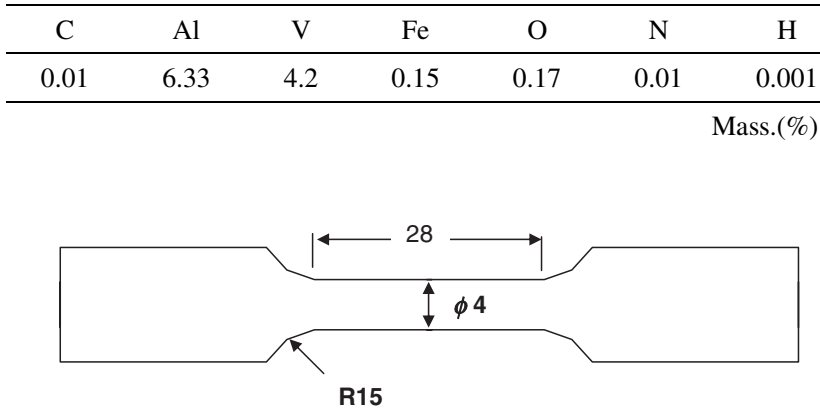

Fig. 1 Tensile test specimens.

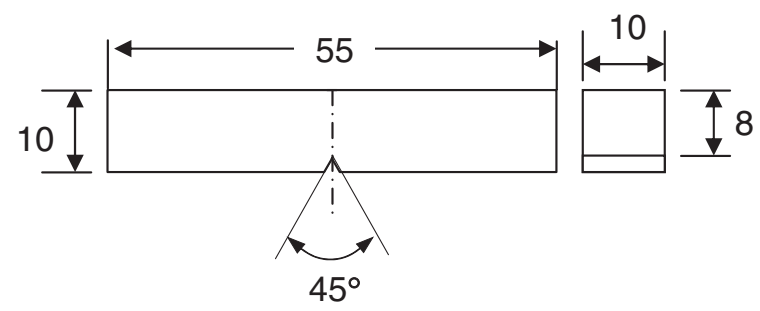

Fig. 2 Charpy impact test specimens.

typical charpy impact specimen. The fatigue test specimens were prepared with $\varphi 8.0$ section. Figure 3 shows a typical fatigue test specimen. Fatigue test specimen notch shapes were machined with a $\mathrm{U}$ notch $(\alpha \mathrm{k}$ : stress concentration coefficient is 2.0) and a $\mathrm{V}$ notch ( $\alpha \mathrm{k}$ : stress concentration coefficient is 3.57). The fatigue test used a rotation bending tester (SHIMAZU Corporation) with a rotating speed of $2800 \mathrm{rpm}$. Microstructures of specimen with and without the OD treatment were observed by optical microscope. An etchant was made with fluoride acid, nitric acid, and water in the ratio of $2: 15: 100$.

Cross sectional hardness of the OD treated specimen was measured by Fischer HM 2000 instrument (Micro Hardness Tester).

$\mathrm{X}$-ray diffraction measurements were carried out using a rotating anode X-ray generator (Rigaku, rint1400, $\mathrm{Cu} \mathrm{k} \alpha$, $50 \mathrm{kV}, 150 \mathrm{~mA}$ ) and a nickel filter. 


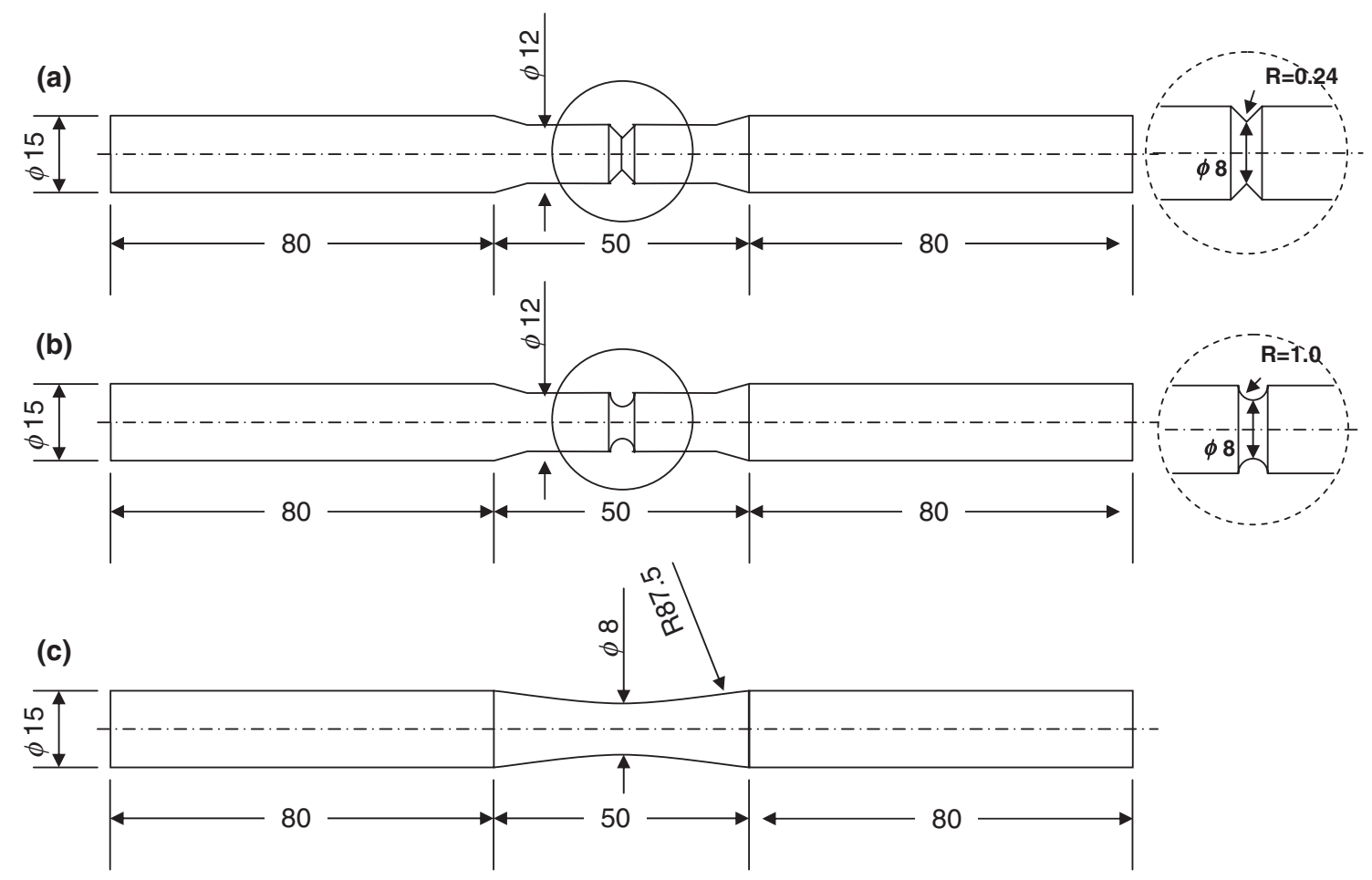

Fig. 3 Fatigue test specimens (a) V-notch (b) U-notch (c) Plane.

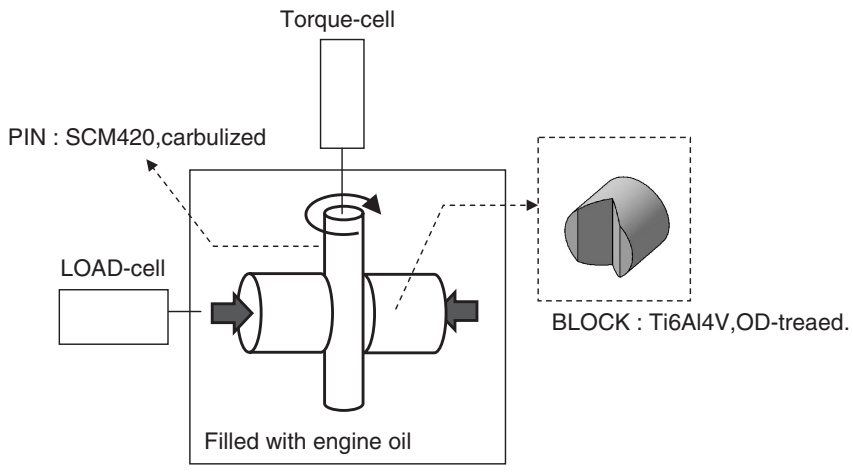

Fig. 4 Schematic drawing of faville seizure test.

Seizure examination, to evaluate seizure characteristics at load, was done using a Faville tester, Daido Kogyo. Outline of the seizure tester is shown in Fig. 4. A center pin rotates, and is loaded on the side by two blocks. The pin was made of carburized SCM420, with an average surface roughness of $3.2 \mu \mathrm{m}$ and a diameter of $6.4 \mathrm{~mm}$. The block was made of Ti6Al4V alloy. Rotational speed of the pin was $300 \mathrm{rpm}$. The tester was soaked in engine oil during testing while evaluating seizure characteristics at load. Residual stress measurements were carried out using a Stresstech instrument. (Ti $\mathrm{k} \alpha, 30 \mathrm{kV}$, $6.7 \mathrm{~mA}$ ). Shot peening condition used glass beads \# 100 $(105-149 \mu \mathrm{m})$, almenstrips A, with an arc-height of $0.4 \mathrm{~mm}$.

\section{Results and Discussion}

\subsection{Surface improvement effect by the OD treatment (Seizure characteristics)}

\subsubsection{Seizure characteristics}

Figure 5 shows the results of the seizure test for the OD

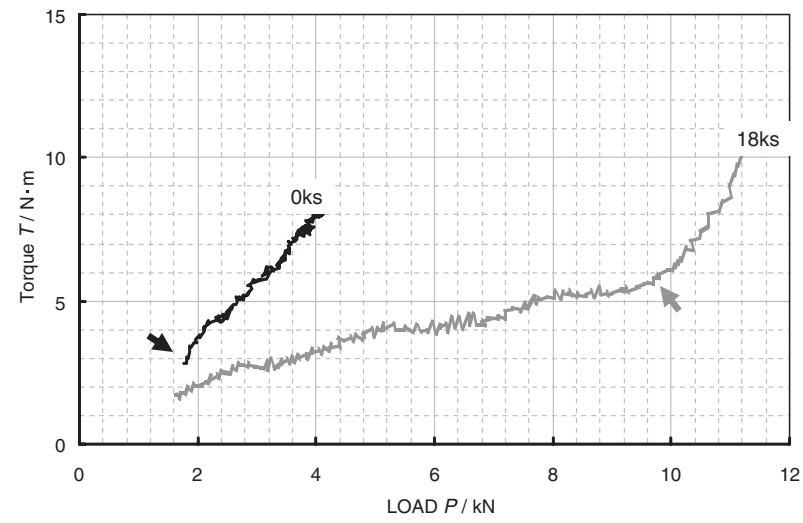

Fig. 5 Relationship between applied load and torque for the non ODtreated and various the OD-treated specimens. (Bold arrows indicate seizure point.)

treated $(973 \mathrm{~K}, 18 \mathrm{ks})$ and the non-OD treated test specimens. The seizure load is judged as the load at which torque suddenly rises (indicated in the figure as $\uparrow$ ). The non OD treated material exhibited a seizure load of less than $2 \mathrm{kN}$. On the other hand, the seizure load increased by 4 times to $8 \mathrm{kN}$ indicating improvement in seizure characteristic. This confirms the positive influence of the surface hardened layer by oxygen on seizure.

Deformation of the surface occurs in the first stage of seizure in titanium. When fresh titanium appears, seizure suddenly occurs. This is a characteristic of titanium alloys. Therefore, we think that seizure toughness depends on surface hardness.

\subsubsection{Surface condition of the OD layer}

Figure 6 displays microstructures and Fig. 7 shows surface hardness changes. The surface hardness of the OD treatment 

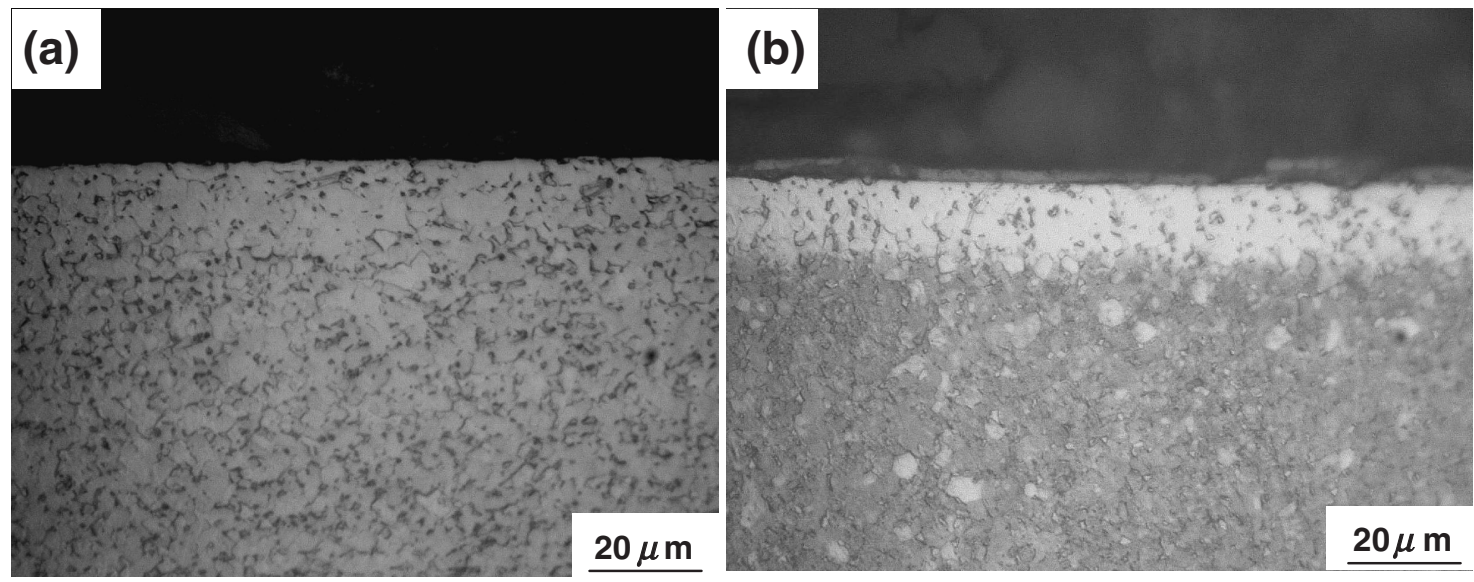

Fig. 6 Surface conditions of OD layer. (a) Untreated (b) OD treated.

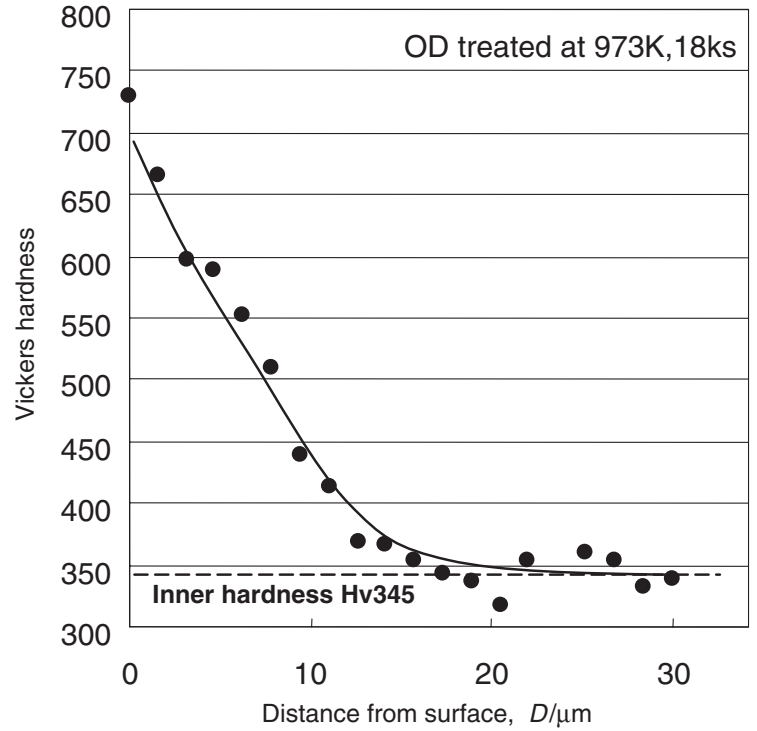

Fig. 7 Change in Vickers hardness with increasing of distance from surface.

increased when compared to the non-OD treated specimens, from $H v 350$ to $H v 750$. It appears that oxygen is in solution at the surface, and it is estimated that the oxygen concentration is high in the surface based on the hardness data. This surface hardening is equivalent to the carburizing of steel, and is an available surface treatment for titanium to increase seizure toughness. ${ }^{12)}$ The results of surface layer X-ray analysis are shown in Fig. 8. Peaks of $\mathrm{TiO}_{2}$ are confirmed for the OD treated material. Comparing XRD date before and after the OD treatment, the $\beta$ (110) peak, is seen to decrease. The ratio of $\alpha / \beta$ varies with the stabilization of elemental oxygen. The surface becomes $\alpha$-rich when compared to the core. It has been reported that fatigue strength decreased in the nitrided layer of notch test specimens. ${ }^{13,14)}$ We checked the OD treated test specimens, in which occurs a similar phenomenon. The oxygen concentration in the surface area increases, and the surface completed $\beta$ phase $\rightarrow \alpha$ phase transformation. As a result, the phase changed from bcc to hcp, and tensile residual stress occurs on the surface. We think this phenomenon (which is the surface volume shrinkage) is factor for decreased strength.

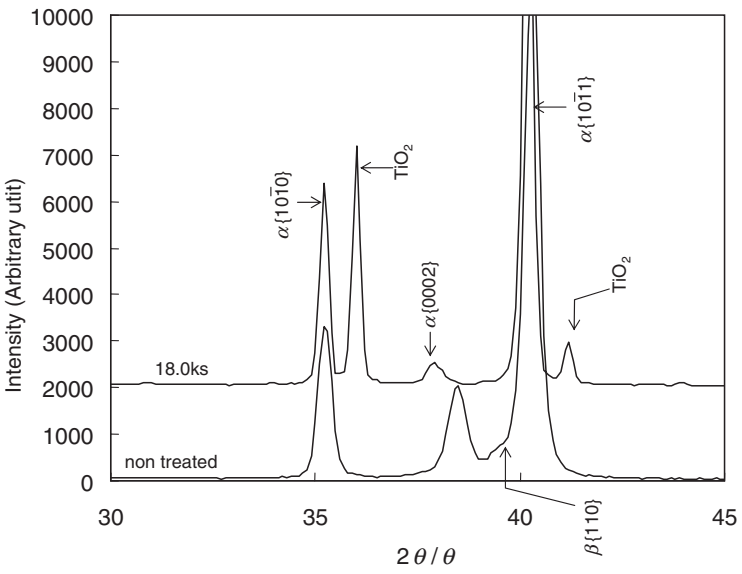

Fig. 8 X-ray diffraction patterns of OD-treated specimens.

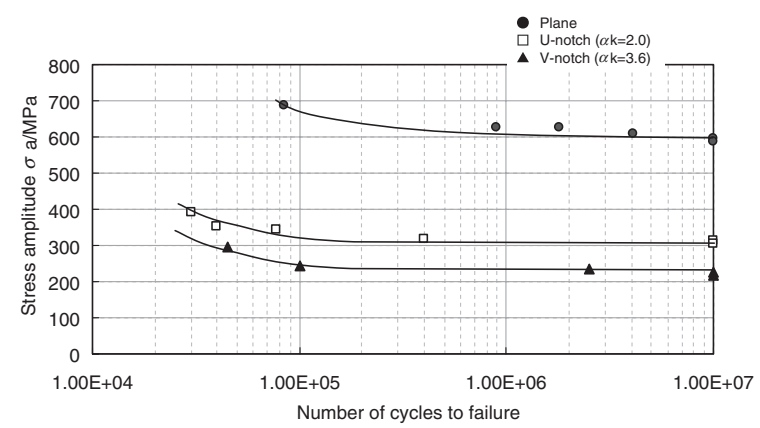

Fig. 9 Results of fatigue tests (without the OD treatment).

\subsection{Influence of surface treatment and its condition on fatigue strength}

\subsubsection{Influence of notch on fatigue strength}

Figure 9 shows the fatigue strength of plane and notched specimens for fatigue test. The fatigue strength of the plane specimens is $600 \mathrm{MPa}$, which decreased to $315 \mathrm{MPa}$ with a U notch, for fatigue strength reduction of about $50 \%$. For the $\mathrm{V}$ notch specimen, the fatigue strength deteriorated to $230 \mathrm{MPa}$. Fatigue strength is thus clearly affected by the presence of a notch. 
Table 2 Mechanical properties.

\begin{tabular}{lcccc}
\hline & $\begin{array}{c}\text { TS } \\
(\mathrm{MPa})\end{array}$ & $\begin{array}{c}0.2 \% \mathrm{YS} \\
(\mathrm{MPa})\end{array}$ & $\begin{array}{c}\text { El. } \\
(\%)\end{array}$ & $\begin{array}{c}\text { Absorbed } \\
\text { Energy (J) }\end{array}$ \\
\hline not OD-treated & 1040 & 986 & 17.2 & 40.7 \\
\hline $\begin{array}{l}\text { OD-treated } \\
(973 \mathrm{~K}, 18 \mathrm{ks})\end{array}$ & 1019 & 977 & 17.0 & 40.3 \\
\hline
\end{tabular}

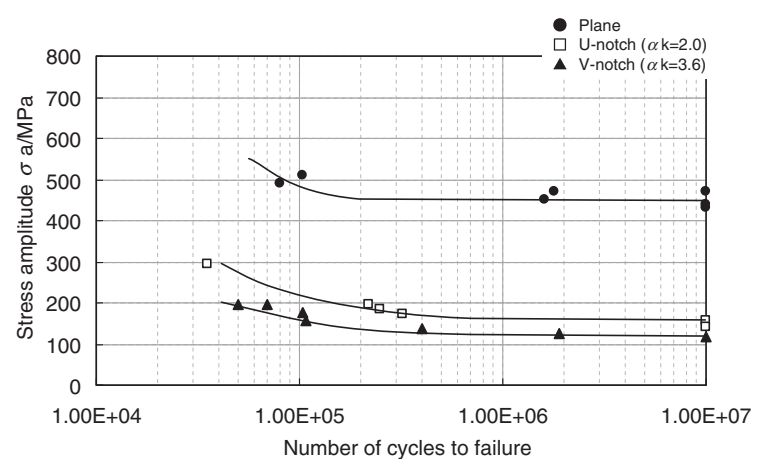

Fig. 10 Result of fatigue tests (with the OD treatment).

\subsubsection{Influence of the OD treatment on static strength}

Table 2 shows the static mechanical properties of the OD treated test specimens. The static mechanical properties, which include strength, elongation, and impact energy, were not affected by the OD treatment. Since the scale layer and the OD treated hardened layer are $50 \sim 60 \mu \mathrm{m}$ in depth, this is a very small percentage of the overall thickness. Therefore, there is not influence on the static mechanical properties.

3.2.3 Influence of the OD treatment on fatigue strength

Figure 10 shows the fatigue strength of the OD treated specimens in fatigue tests. Fatigue strength decreased after the OD treatment was applied. In the OD treated fatigue test specimens, fatigue strength decreased by $460 \mathrm{MPa}$ compared to that of the non-OD treated test specimens. We think this is caused by the surface oxygen diffusion layer. In addition, notch sensitivity increased due to the surface oxidation diffusion layer, and fatigue strength decreased. Furthermore, the fatigue strength of the OD treated U notch and $\mathrm{V}$ notch test specimens decreased to $160 \mathrm{MPa}$ and $120 \mathrm{MPa}$, respectively.

The OD treated specimens are more largely decreasing strength compared with the non-OD treated specimens, the reason is the influence of surface residual stress without shape. The OD treatment phenomenon has the same effect as notch sensitivity by reducing fatigue strength of the material.

\subsection{Improvement method of fatigue strength after the OD treatment}

\subsubsection{Change in fatigue strength by shot peening}

Figure 11 shows the fatigue strength after shot peening, for both OD treated and non-OD treated specimens. In addition, Fig. 12 shows the results of residual stress measurements. The date indicate an improvement in fatigue strength for the OD treated after shot peening test specimen. The cause of this appears to be the surface residual stress. Fatigue strength recovered from $460 \mathrm{MPa}$ to $600 \mathrm{MPa}$ for the OD treated

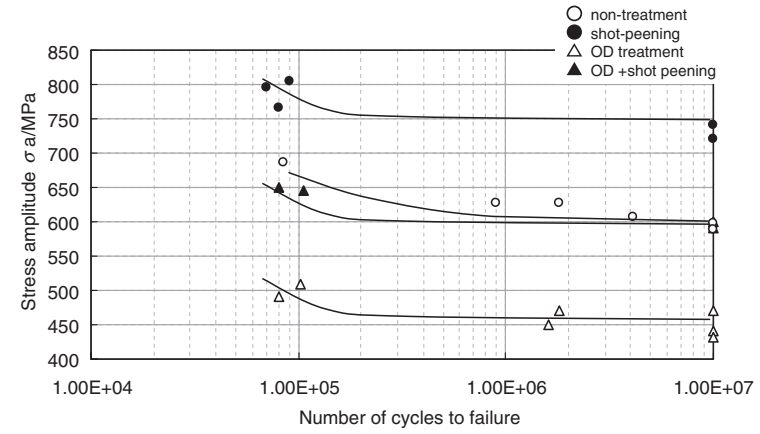

Fig. 11 Results of fatigue test of shot peenig specimens.

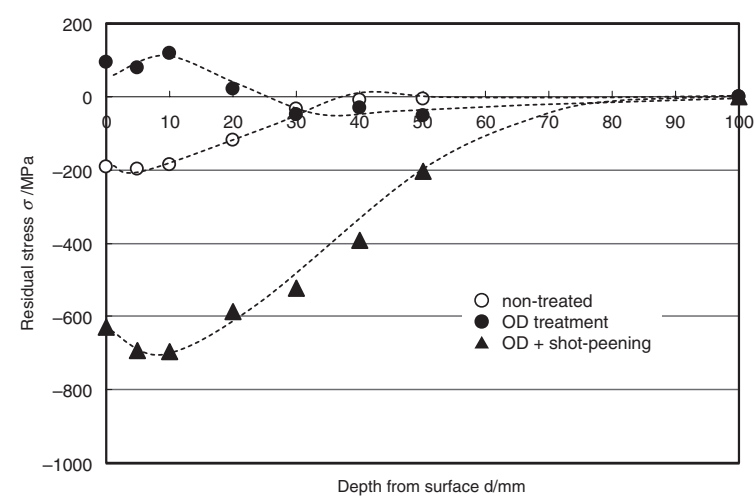

Fig. 12 Residual stress of the OD treated specimens.

specimen after shot peening. Oxygen (an interstitial element) is in solution in the vicinity of the surface, and tensional residual stress occurs in the vicinity of the surface. The surface residual stress is changed to compressive stress of compression from tensile stress by shot peening. Fatigue strength thus recovered to almost the same level as the original strength due to the influence of surface residual stress and the hardened the OD layer.

\section{Conclusion}

The main conclusions are as follows:

(1) Seizure characteristics of Ti6Al4V alloy are improved by applying the OD treatment using oxygen.

(2) A decrease in fatigue strength was obtained due to tensional residual stress induced by the OD treatment.

(3) Tensional residual stress on the surface due to the OD treatment is changed to compressive residual stress by shot peening. As a result, fatigue strength recovered almost to the level as before the OD treatment.

(4) High fatigue strength and good seizure toughness conventionally do not coexist in titanium alloys, however we believe the effects of oxygen (which is an inexpensive, ubiquitous element) treatment can be used to improve these properties.

\section{REFERENCES}

1) W. Urushihara: Titanium Japan 55 (2007) 207-211.

2) H. Fujii, K. Takahashi and Y. Yamashita: Nippon Steel Technical Rev. 378 (2003) 62-67. 
3) Y. Sugisaki and H. Sato: Titanium Zirconium 39 (1991) 191-199.

4) S. Hamai: Netsushori 34 (1994) 35-40.

5) T. Sato and K. Akashi: J. JILM 42 (1992) 650-656.

6) Y. Moriguchi, M. Ochi, H. Ito, I. Tamura and T. Nagata: Titanium Zirconium 24 (1976) 194-198.

7) L. Bendersky and A. Rosen: Eng. Fract. Mech. 20 (1984) 303-311.

8) K. Satoh, M. Hashiba, K. Watanabe, T. Yamashina and K. Yabe: J. Vacuum Soc. Japan 23 (1980) 176-179.

9) H. Takahashi, T. Morita, M. Shimizu and K. Kawasaki: Japan Soc. Mech. Eng. 59 (1993) 9-14.
10) H. Mano, S. Kondo and A. Matsumuro: Japan Inst. Metals 70 (2006) 415-419.

11) S. Takagi, M. Kumagai, Y. Ito, S. Konuma and E. Shimodaira: Tetsuto-Hagane 92 (2006) 24-32.

12) T. Naito: Actual of Carburized Quench (Nikkan Kogyo Shimbun, Tokyo, 1979) pp. 60-62.

13) T. Morita, M. Shimizu and K. Kawasaki: Japan Soc. Mech. Eng. 59 (1993) $76-81$.

14) T. Morita, S. Fuchikawa, J. Komotori, M. Shimizu, K. Minakawa and K. Kawasaki: Japan Soc. Mech. Eng. 67 (2001) 125-131. 